\title{
0 acesso à Justiça como objeto de política pública: o caso da Defensoria Pública do Rio de Janeiro
}

\section{Access to Justice as an Objetct of Public Policy: the Public Defender's Office of the State of Rio de Janeiro}

\author{
Luiz Eduardo Pereira Motta ${ }^{1}$ \\ Marco Aurélio Ruediger ${ }^{2}$ \\ Vicente Riccio $^{3}$
}

\begin{abstract}
Resumo
Este artigo pretende analisar o processo de construção institucional da Defensoria Pública do Estado do Rio de Janeiro. 0 texto discute a sua transformação de uma instituição concebida para tratar de questões jurídicas individuais num espaço de defesa dos direitos difusos, coletivos, e individuais. A nova modelagem institucional se caracteriza pela autonomia em relação ao Poder Executivo e pela existência de garantias institucionais próximas do Poder Judiciário e do Ministério Público. Essa nova modelagem se apresenta num contexto de ampliação da presença do direito na sociedade brasileira, em virtude do fortalecimento dos princípios democráticos estabelecidos pela Constituição Federal de 1988.
\end{abstract}

Palavras-chave: acesso à Justiça; inovação organizacional; advocacia pública.

\begin{abstract}
This article intends to analyze the process of the institutional construction of the Public Defender's Office of the State of Rio de Janeiro. It discusses the change from an office designed to deal with individual legal questions to an institution for the defense of wide-ranging individual and collective rights. The autonomy from the Executive Branch and the existence of institutional guarantees close to the Judiciary and to the Public Prosecution Service characterizes this new institutional model. This new model takes place in the context of the expansion of the presence of rights in Brazilian society due to the strengthening of the democratic principles of the 1988 Federal Constitution.
\end{abstract}

Key words: access to Justice; organizational innovation; public advocacy.

\section{Introdução}

O mundo contemporâneo tem sido marcado por profundas transformações políticas, econômicas e sociais. A emergência de uma sociedade cada vez mais integrada pelas tecnologias da informação e pela lógica do mercado tem sido, por outro lado, acompanhada do surgimento de novos conflitos sociais. Esse contexto - em que o Estado tem sua capacidade de intervenção reduzida por pressões de natureza fiscal - é, ao mesmo tempo, marcado pela presença crescente do direito como um instrumento de integração social. Tal processo paradoxal evidencia-se com maior vigor nas novas democracias, em especial nos países emergentes. Assim, o direito vê-se

\footnotetext{
1. Doutor em sociologia pelo IUPERJ. Professor da Escola Brasileira de Administração Publica e de Empresas da Fundação Getulio Vargas - EBAPE/FGV. Endereço: Praia de Botafogo,190 - sala 505. Botafogo - Rio de Janeiro/RJ - Brasil - CEP: 22250-900. E-mail: luizeduardopmotta@yahoo.com.br.

2. Doutor em Sociologia pelo IUPERJ. Professor da Escola Brasileira de Administração Publica e de Empresas da Fundação Getulio Vargas - EBAPE/FGV e Coordenador do Curso de Mestrado em Administração Pública da EBAPE/FGV. - Endereço: Praia de Botafogo,190 - sala 505 - Botafogo - Rio de Janeiro/RJ Brasil - CEP: 22250-900. E-mail: ruediger@fgv.br.

${ }^{3}$ Doutor em Sociologia pelo Instituto Universitário de Pesquisa do Rio de Janeiro - IUPERJ. Professor da Escola Brasileira de Administração Publica e de Empresas da Fundação Getulio Vargas - EBAPE/FGV. Endereço: Praia de Botafogo,190 - sala 525. Botafogo - Rio de Janeiro/RJ - Brasil - CEP: 22250-900. E-mail: vriccio@fgv.br.

Artigo recebido em fevereiro de 2006 e aceito para publicação em abril de 2006.
} 
em um duplo âmbito; de um lado, os imperativos de natureza econômica, e de outro, a afirmação dos princípios constitucionais como os elementos estruturantes de sua ação no mundo social.

O acesso à Justiça torna-se, então, um dos elementos centrais do processo de democratização nas sociedades contemporâneas. Essa marca pode ser observada em sua origem nos países centrais e na busca pelo provimento de serviços judiciais aos extratos sociais mais necessitados. Por sua vez, esse movimento não ficou restrito às democracias maduras, podendo ser observado em sociedades como a brasileira. Dos elementos indicadores da ampliação do acesso à Justiça, podemos apontar a constituição das defensorias públicas no Brasil a partir da década de 1950.

Por essa razão, este artigo pretende discutir a criação de instrumentos de acesso à Justiça na democracia contemporânea, tendo como objeto de análise uma instituição jurídica que vem se notabilizando como um dos principais veículos nesse sentido, a Defensoria Pública do Rio de Janeiro. A despeito de sua criação já nos anos 1950, esse instituição tem se destacado no cenário jurídico brasileiro desde a última década, por sua ampla atuação em diversas áreas - não se restringindo mais aos direitos ditos tradicionais, como família ou cível, mas também no campo dos direitos humanos - e pela incorporação dos "novos" direitos, de características coletivas e difusas. Além disso, tal instrumento jurídico é marcado pela inovação institucional, haja vista que a Defensoria Pública tem autonomia em relação ao Poder Executivo e, em alguns casos, poderes e garantias típicos do Ministério Público e do Judiciário.

Assim, o artigo em questão pretende abordar o problema considerando:

- a origem do acesso à Justiça;

- a constituição da Defensoria;

- contexto de judicialização; e

- conclusão.

Através dessa divisão busca-se esclarecer o surgimento da Defensoria e seu perfil singular em comparação com as instituições de acesso à Justiça existentes. Essa modelagem será abordada levando-se em conta o processo de ampliação da esfera de direitos nas sociedades contemporâneas, especialmente os de natureza difusa e coletiva, que contribuem para a sua formatação. Ao final, o artigo aponta a relação entre o modelo da organização e as peculiaridades do processo de consolidação do regime de direitos na sociedade brasileira contemporânea.

\section{0 acesso à Justiça}

A questão do acesso à Justiça tem sido um dos temas mais recorrentes no debate acerca da efetividade dos sistemas de Justiça, e tem como ponto de partida a obra de Cappelleti e Garth (1988). De acordo com Junqueira (1993), esse tema começou a despertar interesse nos pesquisadores brasileiros nos anos 1980. Contudo, as motivações não eram as mesmas dos cientistas sociais europeus ou estadunidenses - já que estes vinculavam essa questão à expansão dos serviços do welfare state (em meio à crise desse modelo estatal iniciada nos anos 1970) -, nem tampouco se referiam à afirmação de novos direitos de cunho coletivo e difuso, como os do consumidor, meio ambiente, étnico ou sexual. No Brasil, o que prevalecia nos anos 1980 eram os canais alternativos de Justiça, paralelos ao Estado - sendo este identificado como uma representação política autoritária -, e daí a impossibilidade do enfoque ao acesso à Justiça aos canais institucionais oriundos do aparato estatal. A ênfase era, sobretudo, no papel das comunidades na resolução dos seus conflitos, a exemplo do estudo de Santos (1977) sobre a favela do Jacarezinho nos anos 1970.

Ademais, o tema do acesso à Justiça pelo Estado estava diluído e sobredeterminado pelo debate sobre aquele contexto que enfatizava a ampliação da cidadania participativa, da afirmação e garantia das liberdades negati- 
vas $^{3}$ e do papel desempenhado pelos movimentos sociais que então emergiam. Com efeito, na virada da década de 1970 para a de 1980 surgiram novos atores políticos e sociais que passaram a exercer forte pressão por um Estado democrático de direito e uma cidadania ativa.

De acordo com Carvalho (1995) houve, nesse contexto, em primeiro lugar, uma multiplicação de novos agentes coletivos, como as organizações civis e religiosas - caso das comunidades eclesiais de base (CEBs) - , os movimentos sociais urbanos (a exemplo das associações de moradores da favela e de bairros) 4 e as associações profissionais. Em segundo lugar, os sindicatos dos trabalhadores industriais que queriam autonomia em relação ao Estado (sobretudo em relação ao Ministério do Trabalho) e que acabaram constituindo duas organizações nacionais, como a Central Única dos Trabalhadores (CUT) e a Conferência Nacional dos Trabalhadores(CONCLAT). Em terceiro, além da Confederação Nacional dos Bispos do Brasil (CNBB), outras instituições "tradicionais" como a Ordem dos Advogados do Brasil (OAB) e a Associação Brasileira de Imprensa (ABI) se afirmaram como focos de resistência ao governo militar.

A partir dos anos 1970, os princípios e conceitos dos direitos humanos - tanto civis e políticos quanto econômicos e sociais - emergiram como elementos da agenda política, ganhando maior visibilidade com o término do regime militar. Já no início dos anos 1980, os movimentos sociais progressivamente dedicavam-se à promoção dos direitos sociais e econômicos dos setores pobres da população, além de demandarem novos direitos que ampliassem o processo de inclusão social. Assim, iniciou-se a defesa dos direitos dos grupos chamados "minoritários", como negros, mulheres, homossexuais, crianças e portadores de deficiência, além da promoção do direito de moradia, educação, saúde e a defesa do meio ambiente. Essa luta da sociedade civil pelo restabelecimento do estado de direito teve como ponto de apoio os movimentos sociais (PINHEIRO, 2001).

Silva (2002), por sua vez, observa que nessa conjuntura de abertura política os movimentos sociais tornaram-se uma importante referência na avaliação da estrutura e funcionamento do sistema judicial brasileiro, pois constantemente o pressionavam e questionavam. Surgidas especialmente na virada dos anos 1970 para os 1980, tais movimentos reivindicavam além da oferta e melhorias nos serviços públicos, a defesa dos direitos humanos. Além de se constituírem como portadores de reivindicações por emprego, terra, habitação, saúde, transporte, educação, tais movimentos contribuíram para o debate em torno da necessidade de mudanças legislativas e institucionais que garantissem novos direitos individuais e coletivos, sobretudo, para as populações marginalizadas e as já referidas minorias.

Nesse contexto de discussão sobre a ampliação e consolidação da democracia, o tema da reforma do Poder Judiciário foi incorporado à pauta de advogados, juízes, promotores, acadêmicos e militantes de organizações de assistência jurídica e de comitês de direitos humanos. O maior acesso das classes mais desfavorecidas à Justiça, a racionalização e redução dos custos dos serviços judiciários, a simplificação e modificação do processo jurídico nas áreas cível, penal e trabalhista, a representação jurídica de causas coletivas e, finalmente, a mudança na formação e no papel do juiz e dos demais operadores jurídicos (advogados, promotores, procuradores e defensores) foram questões exaustivamente discutidas por especialistas e por diversos grupos da sociedade civil organizada (SILVA, 2002).

O processo ocorrido no Brasil se inscreve no movimento de acesso à Justiça definido classicamente por Cappelletti e Garth (1988) e composto por três ondas:

- a primeira tem como principal característica a extensão da oferta de serviços jurídicos aos setores mais pobres da população;

- a segunda trata da incorporação dos interesses coletivos e difusos como objetos de proteção jurídica; e

\footnotetext{
${ }^{3}$ Sobre as diferenças entre a liberdade negativa e a liberdade positiva(a primeira, de matriz liberal lockeana, significa liberdade do indivíduo em relação ao Estado, enquanto a segunda, de caráter democrático rouseeauniano, corresponde a liberdade do indivíduo no Estado) veja as obras de Isaiah Berlin Quatro ensaios sobre a liberdade, e Norberto Bobbio O futuro da democracia.
}

${ }^{4}$ Segundo Carvalho (1995, p.137), havia no início da década de 1980 mais de 8.000 associações de moradores em todo o país. 
- a terceira inclui a Justiça informal, a ampliação da mediação de conflitos e a simplificação da lei.

Essa "terceira onda" de reforma inclui a advocacia, tanto judicial quanto extrajudicial, por meio de advogados particulares ou públicos, como também o conjunto de instituições e procedimentos adotados para processar e mesmo prevenir disputas nas sociedades modernas. Segundo Gryszpan, a terceira onda

decorreu e, ao mesmo tempo, englobou as anteriores, expandindo e consolidando o reconhecimento e a presença, no Judiciário, de atores até então excluídos, desembocando num aprimoramento ou numa modificação de instituições, mecanismos, procedimentos e pessoas envolvidos no processamento e na presença de disputas na sociedade. $(1999, \text { p.100 })^{5}$

Ao se observar as primeiras experiências a respeito da assistência judiciária, podemos verificar iniciativas na Alemanha dos anos 1920 e na Inglaterra nos anos 1940. Entretanto, foi a partir dos anos 1960 que a idéia de uma assistência judiciária começou a estruturar as concepções de reforma do sistema legal (CAPPELLETTI e GARTH, 1988). Uma iniciativa pioneira, em 1965, nos EUA, foi o Office of Economic Opportunity e que se espalhou, na década de 1970, por diversos países, como a França, Suécia, Holanda, Áustria, Itália e Austrália.

Essa primeira grande onda de reforma foi dividida basicamente em dois grandes modelos: o Sistema Judicare e a remuneração de advogados pelos cofres públicos. O sistema Judicare foi adotado em boa parte dos países da Europa Ocidental, como Áustria, Inglaterra, Holanda, França e Alemanha. Trata-se de um sistema através do qual a assistência judiciária é estabelecida como um direito para todas as pessoas que se enquadrem nos termos da lei. Os advogados particulares, então, são pagos pelo Estado. A finalidade do sistema Judicare é proporcionar aos litigantes de baixa renda a mesma representação que teriam se pudessem pagar um advogado (CAPPELLETTI e GARTH, 1988).

Contudo, esse modelo apresenta limitações, pois ainda que desfaça a barreira do custo, pouco faz para atacar outros obstáculos encontrados pelos pobres. A principal deficiência do modelo é abordar somente questões de natureza individual, negligenciando interesses de grupos sociais. Dado que os pobres encontram muitos problemas jurídicos como grupo, remédios jurídicos meramente individuais são inadequados, pois em muitos casos os problemas são de natureza coletiva. Um exemplo importante são questões de consumidores ou relativas ao meio ambiente. Os modelos de Judicare somente atuariam nas demandas individuais, o que revela uma limitação no seu escopo de ação. Com o surgimento de ações coletivas, novos espaços de defesa da cidadania são abertos, especialmente, por institutos jurídicos destinados à proteção dos interesses difusos (VIANNA e BURGOS, 2002).

O modelo de assistência judiciária com advogados remunerados pelos cofres públicos tem um objetivo diferente do sistema Judicare. Esse modelo, mais conhecido pela sua versão estadunidense, considera que os serviços jurídicos deveriam ser prestados por "escritórios de vizinhança", através de advogados pagos pelo governo e encarregados de promover os interesses dos pobres como classe. De modo distinto dos sistemas Judicare existentes, esse sistema tende a ser caracterizado por grandes esforços para conscientizar as pessoas pobres de seus novos direitos e torná-las desejosas de recorrer a advogados para defendê-las.

No caso das iniciativas americanas, os escritórios são pequenos e localizados nas comunidades pobres, para facilitar o contato e minimizar as barreiras de classe. Em suma, além de apenas encaminhar as demandas individuais dos pobres que são trazidas aos advogados, tal como no sistema Judicare, esse modelo apresenta as seguintes características:

- está próximo dos pobres para auxiliá-los a reivindicar seus direitos e

\footnotetext{
${ }^{5}$ Para Economides (1999, p.72), haveria uma "quarta onda" que exporia as dimensões ética e política da administração da Justiça, indicando, assim, importantes e novos desafios, tanto para a responsabilidade profissional como para o ensino jurídico.
} 
- cria uma categoria de advogados eficientes para atuar pelos pobres como grupo social (CAPPELLETTI e GARTH, 1988).

O desenvolvimento da terceira onda incorporou as demais e permitiu o surgimento de um direito mais responsivo, ou seja, baseado numa perspectiva mais aberta e flexível, em que o sistema jurídico está enraizado num contexto histórico e social e o interesse do Estado não é legitimado a priori (NONET e SELZNICK, 1978). Nessa configuração, a instituição judiciária busca incorporar as tensões do cotidiano. A mediação, a conciliação judicial e a constituição dos Procons (no caso brasileiro) são exemplos de instrumentos adotados para sua efetivação. Grynspan aponta essas características no processo de consolidação da terceira onda, ao afirmar que tal processo

decorreu e, ao mesmo tempo, englobou as anteriores, expandindo e consolidando o reconhecimento e a presença, no Judiciário, de atores até então excluídos, desembocando num aprimoramento ou numa modificação de instituições, mecanismos, procedimentos e pessoas envolvidos no processamento e na presença de disputas na sociedade. (1999, p.100)

Esse processo foi o ambiente por excelência da construção institucional da Defensoria Pública do Rio de Janeiro.

\section{Acesso à Justiça no Brasil}

Um dos primeiros sinais correspondentes às ondas cappellettianas no contexto pré-Constituinte de 1988 foi a criação do Juizado de Pequenas Causas, através da Lei n ${ }^{0}$ 7.244 de 7-11-1984, posteriormente ampliado pela Lei $\mathrm{n}^{\mathbf{0}}$ 9099/95. Outro sinal foram as leis que estabeleceram novas diretrizes para o Ministério Público e o tornaram o principal agente responsável pela proteção de interesses coletivos e difusos: a Lei n⿳0 6.938/81, que o legitimava a promover ações de responsabilidade civil por danos ambientais, e sobretudo a Lei n⿳⺈ 7.347/85, que instituía a ação civil pública.

Já na Constituição Federal de 1988, as ondas cappellettianas de acesso à Justiça firmaram-se no plano normativo através de um conjunto de leis, das quais podem ser destacadas:

- $\quad$ a assistência judiciária integral aos necessitados (art. $5^{\circ}$, LXXIV);

- a instituição dos Juizados Especiais (art.98);

- a elevação da Defensoria Pública à condição de instituição essencial à função jurisdicional do Estado, cabendo-lhe a orientação jurídica e a defesa, em todos os graus, dos necessitados (art.134); e

- a reestruturação do papel do Ministério Público como instituição essencial à função jurisdicional do Estado, incumbindo-lhe atribuições para a defesa da ordem jurídica, do regime democrático e dos interesses coletivos e difusos (art.127 e 129).

De fato, a Constituição Federal de 1988 foi muito influenciada pelos movimentos sociais, já que incorporou um amplo conjunto de garantias e de direitos, sobretudo, no art. $5^{\mathrm{o}}$ em seus 77 incisos, constituindo-se numa autêntica bill of rights, a mais precisa e ampla de toda a história constitucional brasileira.

Uma extensa lista de direitos foram consagrados pela Carta de 1988, justificando sua proclamação como a "Constituição Cidadã". Os direitos constitutivos da cidadania foram significativamente ampliados, pois, como visto anteriormente, ao lado dos direitos tradicionais de natureza individual (civis e políticos) foram incorporados os direitos supra-individuais ou sociais, além de terem sido formadas distintas instâncias (ou espaços públicos estatais) que facilitassem o acesso do cidadão à Justiça. Assim, no plano legal, foram constituídas as três ondas cappellettianas (CARNEIRO, 2002; SADEK, 2000; PINHEIRO, 2001).

Já no período republicano, o auxílio jurídico aos extratos mais necessitados da sociedade foi disciplinado por decreto presidencial (Decreto $\mathrm{n}^{\mathrm{o}} 1.030$ de 14-11-1890), ao tratar da organização da Justiça no Distrito Federal. 
A assistência judiciária é indicada também no Código Civil de 1916, sendo deixado aos Estados a sua efetivação. Com a Revolução de 1930 e o início do período varguista, é criada a Ordem dos Advogados do Brasil (OAB), em cujos estatutos de fundação (1931) consta a obrigatoriedade da prestação de assistência jurídica pelos seus advogados inscritos (art.91 a 93). A Constituição Federal de 1934 também estabeleceu a assistência judiciária (art.113, XXXII), enquanto a Carta de 1937 não a abrigava em seu texto, mas a disciplinava através do Código de Processo Civil de 1939 (art.68).

A assistência judiciária retornou ao texto constitucional com a Carta de 1946, inserida no capítulo dos direitos e garantias individuais (art.141 §35), segundo o qual "o poder público, na forma que a lei estabelecer, concederá assistência judiciária aos necessitados". Dentro desse espírito, a Lei no ${ }^{1} 1.060$ de 5-2-1950 reformulou a disposição legal acerca da assistência judiciária, modificando os artigos do Código de Processo Civil e ampliando a assistência aos necessitados (art. $2^{\circ}$, §único).

O conceito de necessitado estabelecido pela lei não era muito rígido, pois não o vinculava a um teto salarial previamente definido. Além disso, a assistência judiciária abrangia todos os atos do processo até a sua decisão final em última instância. Apesar da Lei 1.060/50 ter representado um salto qualitativo em relação às que lhe precederam, ela ainda não definia a assistência judiciária como um dever do Estado, mas como uma concessão.

Assim, a idéia de assistência judiciária atinge, além de órgãos estatais, todo agente que tenha por objetivo principal essa prestação de serviço; seja por determinação judicial, seja por convênio com o poder público. Nessa situação, estão incluídos os escritórios de advocacia que freqüentemente prestam assistência judiciária, os escritórios modelos das faculdades de direito, as fundações e as ONGS. Já assistência jurídica tem um sentido mais amplo, pois engloba a assistência judiciária e também outros serviços jurídicos não relacionados com o processo, tais como tirar dúvidas e orientar a comunidade quanto às mais diversas questões jurídicas. A Defensoria Pública, por seu turno, é definida

como instituição estatal que abrange todas essas definições, propiciando além da assistência jurídica integral, o efetivo exercício do contraditório e da ampla defesa, mesmo àqueles economicamente suficientes, quando a causa verse sobre direitos indisponíveis, como é o caso dos réus na Justiça criminal, ou em casos de relevante interesse público, na curadoria ao vínculo. (ALVES e PIMENTA, 2003, p.102-103)

No caso do Rio de Janeiro, a Defensoria Pública se caracteriza justamente por adotar tais princípios.

A despeito da imprecisão conceitual da Lei 1.060/50 sobre a assistência judiciária e a indefinição institucional de quem seria o responsável pela execução desse serviço (assistência judiciária do Estado ou OAB), como também em relação à sua forma de instituição, podemos dizer que esse foi o primeiro documento legal a tratar de modo mais sistemático o acesso à Justiça no Brasil, expressando elementos constituídos durante a era Vargas, como a intervenção do poder público estatal no campo social (CUNHA, 2001). A partir dessa lei, foram sendo constituídas assistências judiciárias pelos governos estaduais, em sua maioria sob a coordenação da Procuradoria-Geral dos estados. Contudo, cada unidade federativa apresentou seu próprio modelo organizacional de assistência judiciária. No antigo Estado do Rio de Janeiro, em 1954, foi constituída a carreira de defensor no âmbito da Procuradoria-Geral da Justiça. Era uma carreira paralela à de promotor público: enquanto o Ministério Público ocupava o "quadro A", a Assistência Judiciária ocupava o "quadro B" da Procuradoria-Geral da Justiça. Já no antigo Distrito Federal (depois, Estado da Guanabara), a Assistência Judiciária foi criada em 1958, época em que o defensor público era uma ocupação inicial na carreira do Ministério Público Federal.

\section{A constituição da Defensoria Pública do Estado do Rio de Janeiro e sua evolução}

A Defensoria Pública do antigo estado do Rio de Janeiro foi criada durante o governo Amaral Peixoto (195155) pela Lei $\mathrm{n}^{\circ} 2.188$ de 21-7-1954, e estabelecia os primeiros cargos de Defensor Público, que constituíram a semente da atual Defensoria Pública. Foram apenas seis, e eram cargos isolados, de provimento efetivo. Cabe 
ressaltar que essa lei foi a primeira a utilizar a expressão "defensor público" para designar os agentes estatais incumbidos do patrocínio gratuito aos necessitados (OLIVEIRA, 2000). A formação da Defensoria Pública não se restringiu ao plano da racionalidade legal, motivada pela Lei 1.060/50, mas foi pautada por outros condicionantes - como o voluntarismo caritativo e as relações políticas e pessoais no âmbito local - que nortearam a sua instituição como elemento de prestação de auxílio judiciário.

Com o Movimento Militar de 1964 e sua consolidação legal pela Constituição Federal de 1967/69, a assistência judiciária não foi abortada e permaneceu no âmbito legal através do art.150, §32, e do art.153, §32, que dispunham que "será concedida assistência judiciária aos necessitados na forma da lei". Contudo, tal qual a Carta de 1934 e a de 1946, não havia uma definição institucional de quem seria responsável pelo exercício dessa função.

Apesar do contexto autoritário, é nessa conjuntura que surgem as primeiras manifestações em defesa da criação de uma Defensoria Pública. No final da década de 1960, o Ministério Público do antigo estado do Rio de Janeiro, tendo à frente a Associação do Ministério Público Fluminense - que congregava, à época, Promotores de Justiça e Defensores Públicos do antigo estado do Rio de Janeiro - deu início à realização de congressos nacionais que consolidaram diversos movimentos em favor do Ministério Público e da Defensoria Pública, então denominada Assistência Judiciária.

Se por um lado essas primeiras mobilizações em defesa da organização da Assistência Judiciária não conseguiram concretizar seu objetivo em nível nacional, por outro, a década de 1970 foi um período fundamental na estruturação da Assistência Judiciária no Rio de Janeiro, sobretudo, depois da fusão com o estado da Guanabara. O primeiro sinal de mudança foi o Decreto-lei no 286/70, pelo qual a Assistência Judiciária passou a ser considerada órgão de Estado. Em seguida, com a nova Constituição Estadual, em 23-7-1975 - a partir da fusão dos dois estados, implementada pelo governo militar e com o almirante Faria Lima à frente do processo de transição -, a Assistência Judiciária foi incluída no art.82 como essencial à estrutura política do Estado (ALVES e PIMENTA, 2003).

O grande salto da Defensoria ocorreu a partir da Constituição da República de 1988. Os princípios assegurados pela Carta Magna no seu art.5 $5^{\circ}$, que estruturam as garantias fundamentais dos cidadãos, abordam a Defensoria Pública e o papel do defensor público no processo de constituição do acesso à Justiça. Dos princípios diretamente relacionados com esse papel estão:

XXXII - o Estado promoverá, na forma da lei, a defesa do consumidor;

XXXIV- são a todos assegurados, independentemente do pagamento de taxas:

a) direito de petição aos Poderes Públicos em defesa de direito ou contra a ilegalidade ou abuso de poder;

b) a obtenção de certidões em repartições públicas, para a defesa de direitos e esclarecimento de situações de interesse pessoal;

XXXV - a lei não excluirá da apreciação do Poder Judiciário lesão ou ameaça a direito;

LV - aos litigantes, em processo judicial ou administrativo, e aos acusados em geral, são assegurados o contraditório e ampla defesa, com meios e recursos a ela inerentes;

LXXIV - o Estado prestará assistência jurídica integral e gratuita aos que comprovarem insuficiência de recursos.

A disposição legal abre um novo caminho para o acesso à Justiça no país, e a Defensoria Pública, pela primeira vez, é um elemento central na prestação jurisdicional. Aí, não mais existe a idéia de concessão de prestação de assistência judiciária, mas a definição de que o Estado tem o dever de oferecer os meios adequados para a defesa do cidadão. A alteração do termo assistência judiciária para assistência jurídica configurou um novo tipo de 
ação para os operadores do direito situados no campo do acesso à Justiça, pois, como foi dito antes, a assistência jurídica não apenas compreende o patrocínio gratuito da causa, mas abrange também os custos e as despesas (judiciais ou não) ligados ao processo, além do direito à informação, consultoria jurídica e conciliação entre as partes.

Nesse aspecto, a Constituição do Rio de Janeiro de 5-10-1989 tomou a dianteira em relação às outras unidades federativas. Nessa Carta constitucional, o campo de atuação da Defensoria Pública ultrapassa as normas estabelecidas pela CF/88. Em primeiro lugar, o Procurador-Geral da Defensoria Pública tem legitimidade para propor ação direta de inconstitucionalidade de leis ou atos normativos estaduais e municipais em face da Constituição Estadual (CERJ/89, art.162). Em segundo lugar, estabelece uma novidade no campo de ação dessa instituição: além dos direitos individuais - tradicionalmente representados pelos defensores públicos -, também inclui os direitos coletivos e difusos.

Portanto, a Defensoria Pública do Rio de Janeiro, definida pela Constituição Estadual como um instrumento do regime democrático, tornou-se, do ponto de vista legal, uma referência institucional na questão do acesso à Justiça e na defesa dos direitos humanos: ela incorpora não somente a primeira onda cappelletiana (ampliação de serviços jurídicos aos pobres), mas também os da segunda e terceira ondas (novos direitos, como o ambiental). Além disso, destacam-se como seu público-alvo atores que representam novas demandas, como os ambientalistas, os consumidores ou aqueles que até então não contavam com suficiente respaldo legal e institucional na defesa dos seus direitos, como é o caso das mulheres vítimas de violência, dos menores e dos idosos. ${ }^{6}$

O art.179 da Constituição Estadual expõe também os princípios institucionais que regem a Defensoria Pública, como a unicidade, a impessoalidade e a independência funcional. Por unicidade, entende-se que a Defensoria Pública corresponde a um todo orgânico, sob uma mesma direção, mesmos fundamentos e mesmas finalidades. O princípio da impessoalidade assegura essa unidade, pois permite, por exemplo, que um defensor atue no mesmo processo de um colega em caso de substituição, sem qualquer tipo de alteração na própria relação processual. Já o princípio da independência funcional representa a autonomia dessa instituição perante os demais órgãos estatais, estando imune a qualquer interferência política. Esse princípio também expressa a autonomia do defensor público para seguir suas próprias convicções, fundamentadas no seu conhecimento jurídico e desvinculadas da opinião de sua chefia, a quem está subordinado apenas do ponto de vista administrativo. ${ }^{7}$

O processo de seleção dos defensores públicos e as garantias que lhes são asseguradas indicam essa maior autonomia institucional. O ingresso na carreira é por concurso público de provas e títulos, ${ }^{8}$ sendo vedado o exercício privado da advocacia. ${ }^{9}$ Com relação às garantias institucionais do cargo, podemos citar a inamovibilidade, a irredutibilidade de vencimentos ${ }^{10} \mathrm{e}$ a estabilidade ${ }^{11}$ após dois anos de efetiva atividade funcional. No tocante às suas prerrogativas no exercício profissional, deve-se registrar o direito que os defensores têm de:

- requisitar das instituições públicas e privadas certidões, exames, perícias, vistorias, diligências, processos, documentos, informações, esclarecimento e providências;

- comunicar-se pessoal e reservadamente com o preso, tendo livre acesso e trânsito em qualquer local e dependência em que ele se encontrar; e

\footnotetext{
${ }^{6}$ CE.RJ/89, art. 179: "A Defensoria Publica é instituição essencial à função jurisdicional do Estado, incumbido-lhe, como expressão e instrumento do regime democrático, fundamentalmente, a orientação jurídica integral e gratuita, a postulação e a defesa, em todos os graus e instâncias, judicial e extrajudicialmente, dos direitos e interesses individuais e coletivos dos necessitados, na forma da lei".

${ }^{7}$ CERJ/89, art. 181, III.

${ }^{8} \mathrm{CERJ} / 89$, art. 181 , I, a

${ }^{9} \mathrm{CERJ} / 89$, art. 181 , III.

${ }^{10}$ CERJ/89, art. 182.

${ }^{11}$ CERJ/89, art. 181, I, g.
} 
- ter livre acesso e trânsito em estabelecimentos públicos e naqueles destinados ao público, no exercício de suas funções. ${ }^{12}$

Dessa maneira, as prerrogativas dos defensores indicam uma inovação sem paralelos, pois ampliam a sua capacidade de ação. Tais atribuições permitem, por seu turno, que o defensor tenha uma série de garantias para a defesa de seu cliente em face das ações do próprio Estado. Ao dispor desse modo, a legislação estabelece um tipo de organização na qual o acesso à Justiça é viabilizado pelo Estado, e contra o próprio Estado. Em tal modelo, há a superação do modelo de assistência judiciária em que o problema de um indivíduo é visto por um prisma particularizado e localizado. As garantias indicam o novo papel conferido à instituição, de guarda não somente dos direitos individuais, mas também dos direitos coletivos e difusos. Essa caracterização pública da Defensoria pode ser observada na sua divisão por núcleos, em especial os de caráter temático.

Uma inovação importante no âmbito da Defensoria Pública do Rio de Janeiro é a sua divisão em núcleos temáticos. A adoção de tal formato permite que direitos coletivos, difusos e individuais sejam defendidos pela instituição. Ao se posicionar dessa maneira, há uma clara superação dos modelos de assistência judiciária fundados exclusivamente em demandas individuais. Assim, os núcleos trabalham questões relativas aos direitos humanos, da criança e do adolescente, da mulher e do idoso, referentes à habitação, Polícia Militar, aos portadores de necessidades especiais e às pessoas jurídicas sem fins lucrativos. Essa variedade de especializações indica um modelo mais amplo de instituição de defesa de direitos, mais aberta a uma perspectiva de direito mais flexível e responsiva diante do meio social.

A defesa e a garantia de defesa dos direitos humanos dos indivíduos ante o aparato repressivo do Estado tem sido uma das principais marcas da Defensoria quando esta se confronta com o Estado por meio de seus núcleos que atuam no campo dos direitos humanos. É o caso do núcleo do sistema penitenciário (Sispen), do núcleo da criança e adolescentes (CDEDICA) e do núcleo de direitos humanos (Nudedh). O mesmo pode ser dito quando se trata do núcleo da Fazenda Pública, que apesar de tratar de casos individuais, é um dos principais canais da instituição junto ao "homem comum" quando este se defronta com o Estado em questões relacionadas às políticas públicas, particularmente na área da saúde.

Isso também pode ser visto quanto aos núcleos que tratam dos idosos, de mulheres e de deficientes físicos, pois representam os interesses de grupos específicos, que até recentemente não encontravam um espaço público estatal (no campo jurídico) que atendesse a tal tipo de demanda. Portando, o caráter inovador da ação da Defensoria Pública está na ação de seus núcleos em relação às demandas de natureza coletiva. Tal característica é distinta da perspectiva liberal que estruturou boa parte das políticas de assistência judiciária no século passado, marcadas pela prestação de serviços jurídicos por advogados particulares contratados pelo Estado. O modelo adotado pelo Defensoria é baseado numa burocracia com grande flexibilidade, pois o defensor tem liberdade de ação e de entendimento das questões jurídicas. Essa construção, por sua vez, adapta-se a uma perspectiva democrática de ação em defesa dos direitos individuais, coletivos e difusos.

Como se pode verificar, a forma de estruturação da Defensoria Pública do Rio de Janeiro a diferencia de suas congêneres de outros estados, no que concerne aos vencimentos, organização da carreira, quantidade de defensores em atividade, dotação orçamentária, atribuições do Defensor Público Geral e do Conselho etc. A referência institucional da organização fluminense ampliou-se, principalmente, com a criação dos núcleos temáticos, ao incorporarem as demandas de direitos coletivos e difusos. Pode-se perceber que os temas dos núcleos têm se desdobrado e ampliado de acordo com a conjuntura - como no caso do CDEDICA e do Núcleo dos Direitos Humanos -, o que mostra que cada vez mais os direitos fundamentais são levados em conta na estruturação do contrato democrático contemporâneo. A modelagem da organização permite que as dinâmicas de consolidação de direitos e de sua eventual ampliação sejam incorporadas por seus núcleos.

\footnotetext{
${ }^{12}$ CERJ/89, art. 181, IV.
} 
Com efeito, no decorrer dos anos 1990 houve um crescimento de demandas e uma maior diversificação dos núcleos especializados. Além dos citados, destacam-se o Núcleo Especial de Direitos da Mulher e de Vítimas de Violência (Nudem), o Núcleo Especial de Atendimento à Pessoa Idosa (Neapi), o Núcleo de Loteamentos Irregulares, o Núcleo de Terra e Habitação, o Núcleo da Polícia Militar, o Núcleo de Atendimento aos Portadores de Necessidades Especiais (Nucompe) e o Núcleo de Atendimento às Pessoas Jurídicas sem Fins Lucrativos (Nupejur).

Na capital, os núcleos de primeiro atendimento estão situados nos seguintes bairros: Anchieta, Bangu, Barra da Tijuca, Botafogo, Campo Grande, nos bairros da Central, na Ilha do Governador, Irajá, Jacarepaguá, Madureira, Méier, Pilares, Ramos, Santa Cruz, São Cristóvão e em Vila Isabel. No interior, a Defensoria Pública atua em todos os municípios, não obstante haja diferenças estruturais entre as defensorias do interior: nas grandes cidades atuam diversos defensores, enquanto nas de menor porte só há um defensor público atuando na comarca.

A última conquista legal da Defensoria Pública do Rio de Janeiro - pelo menos até a aprovação da Reforma Judiciária em 2005 -, foi a Lei Complementar $n^{\circ}$ 95/2000, que altera alguns artigos da Lei complementar $n^{\circ}$ 6/77 e visa reestruturar administrativa e financeiramente a Defensoria Pública Geral do Rio de Janeiro. O aspecto mais importante da lei foi ampliar ainda mais a autonomia do Defensor Público Geral, no mesmo modelo do Ministério Público. Se anteriormente o Defensor Público Geral tinha o seu cargo no mesmo patamar de um secretário de Estado, podendo ser afastado de sua função pelo governador; agora, com essa lei, só pode ser destituído pelo voto da maioria absoluta da Assembléia Legislativa em caso de abuso de poder, conduta incompatível ou grave omissão nos deveres do cargo, mediante:

- representação de $1 / 5$ dos deputados estaduais;

- representação do governador do estado; e

- representação de 2/3 dos membros em atividade da Defensoria Pública.

Desse modo, a Defensoria Pública desloca-se da esfera do Poder Executivo, tornando-se uma instituição pública estatal autônoma em relação aos demais poderes e equiparada ao Ministério Público e à Magistratura.

\section{0 contexto de judicialização}

Um fator preponderante na expansão da Defensoria Pública fluminense é o contexto de judicialização da política e das relações sociais. A expansão do direito como um instrumento cada vez mais presente no cotidiano também ocorre no Brasil, mesmo sendo uma jovem democracia. Esse processo vem se apresentando continuamente no domínio das atividades econômicas e do trabalho a partir da década de 1970. Segundo Commaille (2000), ele é "observado, de modo mais amplo, naquelas relações entre o cidadão e o Estado; ou, ainda, na gestão das relações entre os indivíduos, no seio da esfera privada." (2000, p.242). Ou seja, o direito se torna um recurso explorado pelos mais distintos atores sociais para lidar com conflitos surgidos no interior da sociedade. A expansão do direito também é acompanhada de novos institutos jurídicos, que buscam assegurar interesses difusos e coletivos, e por princípios constitucionais abertos. Assim, a gramática dos direitos fundamentais passa a influenciar continuamente as decisões judiciais.

Esse processo se acentuou especialmente pelo fato de que

pela primeira vez na história, uma Constituição definiu os objetivos fundamentais do Estado, e ao fazêlo orientou a compreensão e interpretação do ordenamento constitucional pelo critério do sistema de direitos fundamentais [...]. Espera-se, conseqüentemente, que o sistema de direitos constitucionais, visto como expressão da ordem de valores, oriente a interpretação do ordenamento constitucional em seu conjunto. (CITTADINO, 2002, p.26) 
Nesse caso, o tipo de construção jurídica está baseado em princípios abertos, que procuram trabalhar "elementos normativos (lei), extranormativos (usos e costumes) e metanormativos (valores e postulados morais)." (CITTADINO, 2002, p.29). Tal característica vai permitir que o processo de judicialização da política se apresente nos países democráticos - que têm como característica a presença das cortes e dos juízes - como elemento importante na definição de políticas públicas outrora limitadas a outros ramos do Estado, como o Legislativo e o Executivo. Outro ponto é o fato de que instâncias não-judiciárias de decisão passam a ser influenciadas cada vez mais por regras e procedimentos de feição judicial (TATE, 1995). Nesse sentido, o mundo do direito e do Judiciário se transforma numa variável cada vez mais relevante na condução e definição das políticas públicas.

De fato, afirmar que a política estaria confinada ao processo legislativo e a seus atores tradicionais (partidos políticos, por exemplo) seria bastante simplista. Como afirma Farejohn (2003), os tribunais têm se mostrado cada vez mais propensos a limitar e regular o poder das instituições legislativas e administrativas. Isso demonstra um papel maior dos juízes no contexto das democracias contemporâneas, em que sua atuação é considerada de maneira ambígua, seja em virtude de sua capacidade de exprimir demandas originadas externamente ao sistema político, seja em função das críticas recebidas pelo excesso de intervenção nesses domínios. Apesar das opiniões controversas, são verificadas duas características nesse processo:

- a crescente fragmentação do Poder Legislativo e os limites impostos à sua capacidade de atuar em relação às políticas públicas e os programas de governo;

- reconhecimento dos tribunais como espaços nos quais se pode buscar a proteção de valores e direitos contra abusos do poder político.

Além disso, outros elementos típicos dos regimes democráticos contribuem para a expansão do processo de judicialização. É o caso da separação de poderes, da política de direitos, dos grupos de interesse, das Cortes Supremas e, sobretudo, do ativismo judicial. Assim, se antes o Judiciário era um poder periférico, encapsulado em sua lógica interna, distante da agenda pública e dos atores sociais, atualmente ele se mostra uma instituição central às democracias - particularmente em relação à brasileira -, no que se refere à sua intervenção no âmbito social e político (VIANNA et al, 1999).

Assim, longe de ser um instrumento enfraquecedor do processo democrático e de suas instituições representativas, o incremento da participação do direito na vida social se transforma em potencial espaço de inversão de lógicas excludentes, especialmente, pela constituição de sistemas constitucionais baseados na garantia dos direitos fundamentais. Numa sociedade como a brasileira, esse movimento traz consigo as demandas por maior democracia e a imposição de limites ao tradicionalismo. Essa nova realidade impõe novos modelos organizacionais de defesa de direitos, e tal processo se assemelha ao histórico da Defensoria Pública do Rio de Janeiro, fruto de uma marcha, por vezes interrompida, em direção à construção democrática.

\section{Conclusão}

Como foi observado no decorrer deste artigo, o processo de construção de uma organização destinada a assegurar o acesso à Justiça no Estado do Rio de Janeiro derivou de um processo social marcado pela busca da ampliação da esfera de proteção dos direitos individuais, coletivos e difusos. Tal processo, por sua vez, está ligado à dinâmica democrática da sociedade brasileira contemporânea, marcada por dilemas relativos à adaptação à ordem econômica internacional e às demandas por integração interna de extratos sociais até então excluídos do exercício formal das garantias do contrato social.

As garantias institucionais conferidas à Defensoria Pública explicitam seu papel de agente não apenas de interesses individuais, mas também de guardiã de interesses coletivos e difusos. Ao se constituir como uma instituição distinta dos modelos prévios de acesso à Justiça, e de escopo maior, sua origem está marcada pelo processo em curso na sociedade brasileira, e na fluminense em particular. 
A ampliação de direitos num quadro de desigualdade não significa que tal processo seja destinado ao sucesso ou ao fracasso. Na realidade, suas contradições indicam que experiências bem-sucedidas podem ser construídas em contextos adversos e de alta complexidade. Nesse sentido, a modelagem organizacional da Defensoria Pública do Rio de Janeiro é o resultado desse movimento, e indica o desafio posto a tais estruturas institucionais, o que reforça ainda mais a relação entre organização e ambiente. 


\section{Referências}

ALVES, C. B.; PIMENTA, M. G. Acesso à Justiça em preto e branco: retratos institucionais da Defensoria Pública. Rio de Janeiro: Lumen Juris , 2003.

CAPPELLETTI, M.; GARTH, B. Acesso à Justiça. Porto Alegre: Sérgio Antonio Fabris Editor, 1988.

CARNEIRO, P. C. P. Acesso à Justiça: Juizados Especiais e a ação civil pública. Rio de Janeiro: Forense, 2002.

CARVALHO, J. M. Desenvolvimiento de la ciudadania en Brasil. México: Fondo de Cultura, 1995.

CITADINO, G. Judicialização da política, constitucionalismo democrático e separação dos poderes. In: VIANNA, L. W. (Org.). A democracia e os três poderes no Brasil. Belo Horizonte: Editora da UFMG; Rio de Janeiro: luperj/Faperj, 2002.

COMMAILLE, J. De la sociologie juridique à une sociologie politique du droit. In: COMMAILLE, J.; DUMOULIN, L.; ROBERT, C. (Org.). La juridicisation du politique: leçons scientifiques. Paris: LGDJ, 2000.

CUNHA, L. G. S. Acesso à Justiça e assistência juridica em São Paulo. In: SADEK, M. T. (Org.). Acesso à Justiça. São Paulo: Konrad Adenauer, 2001.

ECONOMIDES, K. Lendo as ondas do "movimento de acesso à Justiça": epistemologia versus metodologia? In: CARVALHO, J. M. (Org.). Cidadania, Justiça e violência. Rio de Janeiro: FGV, 1999.

FAREJOHN, J. Judicializing politics, politicizing law. Hoover Digest, n.1, 2003.

GRYNSPAN, M. Acesso e recurso à Justiça no Brasil: algumas questões. In: CARVALHO, J. M. (Org.). Cidadania, Justiça e violência. Rio de Janeiro: FGV, 1999.

JUNQUEIRA, E. A sociologia do direito no Brasil. Rio de Janeiro: Lumen Júris, 1993.

NONET, P.; SELZNICK, P. Law and society in transition: towards responsive law. New York: Octagon Books, 1978.

OLIVEIRA, M. B. A Defensoria Pública como garantia de acesso à Justiça. Revista de Direito da Defensoria Pública: Cejur, Rio de Janeiro, 2000.

PINHEIRO, P. S. Transição política e não-Estado de Direito no Brasil. In: PINHEIRO, P. S.; SACHS, I.; WILHEIM, J. (Org.). Brasil: um século de transformações. São Paulo: Cia das Letras, 2001.

SADEK, M. (Org.). Justiça e cidadania no Brasil. São Paulo: Sumaré, 2000.

SANTOS, B. S. The law of the oppressed: the construction and reproduction of legality in Pasargada Law. Law and Society Review, v.12, n.5, p.5-126, 1977.

SILVA, C. A. Acesso à Justiça: uma leitura dos direitos e da cidadania no Brasil contemporâneo. São Paulo: IFCH/Unicamp, 2002.

TATE, C. N. Why the expansion of judicial power? In: TATE, C. N.; VALLINDER, T. (Org.). The global expansion of Judicial Power. New York: New York University Press, 1995.

VIANNA, L. W. et al. A judicialização da política e das relações sociais no Brasil. Rio de Janeiro: Revan, 1999.

; BURGOS, M. Revolução processual do direito e democracia progressiva. In: VIANNA, L. W. (Org.). A democracia e os três poderes no Brasil. Belo Horizonte: Editora da UFMG: Rio de Janeiro: luperj/Faperj, 2002. 